\title{
Influence of Enogen Feed corn and conventional yellow dent corn in pelleted or meal-based diets on finishing pig performance and carcass characteristics
}

\author{
Hadley R. Williams ${ }^{\dagger, 1}$, Mike D. Tokach ${ }^{\dagger}$, Jason C. Woodworth ${ }^{\dagger}$, Joel M. DeRouchey ${ }^{\dagger}$, \\ Robert D. Goodband ${ }^{\dagger}$, and Jordan T. Gebhardt ${ }^{\ddagger}$, \\ ${ }^{\dagger}$ Department of Animal Sciences and Industry, College of Agriculture, Kansas State University, Manhattan, KS \\ 66506, USA and Department of Diagnostic Medicine/Pathobiology, College of Veterinary Medicine, Kansas \\ State University, Manhattan, KS 66506, USA
}

\begin{abstract}
Genetic modification of corn has enhanced the use of different corn hybrids in animal agriculture. Enogen Feed corn, developed by Syngenta Seeds (Downers Grove, IL), has potential for use in livestock diets due to increase $\alpha$-amylase enzyme in the corn thus improving starch digestibility. In addition, the pelleting process also increases starch gelatinization which increases its digestibility by the pig, increasing growth rate and improving feed efficiency. Therefore, pelleting Enogen Feed corn might prove to provide a greater response in growth performance than conventional yellow dent corn. Thus, the objective of this experiment was to determine the effects of corn source and diet form on growth performance and carcass characteristics of finishing pigs. A total of 288 pigs $(53.0 \pm 0.5 \mathrm{~kg})$ were used with eight pigs per pen and nine pens per treatment in a $72-d$ study. Treatments were arranged in a $2 \times 2$ factorial

with main effects of corn source (Enogen Feed corn or conventional yellow dent corn) and diet form (meal or pellet). For overall (d 0 to 72) performance, no interactions between corn source and diet form were observed. There was a tendency $(P<0.10)$ for slightly improved average daily gain (ADG) and gain:feed ratio $(\mathrm{G}: \mathrm{F})$ for pigs fed conventional yellow dent corn compared to those fed Enogen Feed corn. For feed form, pigs fed pelleted diets had increased $(P<0.001)$ ADG and G:F compared to pigs fed meal diets. For carcass characteristics, pigs fed pelleted diets had increased hot carcass weight compared to pigs fed meal diets $(P<0.001)$. In summary, feeding pelleted diets to finishing pigs increased ADG and improved feed efficiency compared to those fed meal-based diets. There were no major differences between observed corn sources or interactions between corn source and diet form on growth performance.
\end{abstract}

Key words: Carcass, Enogen Feed corn, finishing pigs, growth, meal, pellet

Published by Oxford University Press on behalf of the American Society of Animal Science 2021. This work is written by (a) US Government employee $(s)$ and is in the public domain in the US.

Transl. Anim. Sci. 2021.5:1-10 doi: 10.1093/tas/txab092

\section{INTRODUCTION}

Cereal grains provide most of the dietary energy in swine diets. Corn is a widely available energy source in the United States and is commonly used in swine diets. Along with ample availability, corn has increased energy density compared to

${ }^{1}$ Corresponding author: hadley1@ksu.edu

Received January 11, 2021.

Accepted May 19, 2021. other cereal grains. As genetic modification of corn improves, use of corn hybrids in the livestock industry has increased, and studies have observed increased in ADG and improved G:F when corn hybrids with specialized nutritional traits, like high lysine and high oil corn, are fed compared to conventional yellow dent corn (O'Quinn et al., 2000; Hastad et al., 2005). Enogen Feed corn contains an $\alpha$-amylase enzyme trait, which is used in the ethanol industry to reduce the viscosity of the corn mash and improve the efficiency of ethanol 
production. Increase of the $\alpha$-amylase enzyme in the corn helps increase the conversion of corn starch to sugar to provide more energy for beef cattle (Brinton, 2019). Ochonski et al. (2021) fed Enogen Feed corn to finishing pigs and observed a tendency for increased daily gain compared to pigs fed conventional yellow dent corn but did not find differences in feed efficiency. Conversely, Williams et al. (2020) observed no difference in growth performance when feeding Enogen Feed corn in the diets compared to conventional yellow dent corn. Diets were fed in meal form in both of these studies.

Research has proven that feeding pelleted diets increased ADG and G:F (Wondra et al., 1995; De Jong et al., 2013a, 2013b; Nemechek et al., 2015). Pelleting pig diets improves performance by increasing nutrient digestibility and reducing feed wastage (Ball et al., 2015). During pelleting, starch gelatinization occurs which allows the pig to better utilize the starch. Truelock et al. (2020) evaluated pelleting Enogen Feed corn and conventional yellow dent corn with different pellet die length to diameter $(\mathrm{L} / \mathrm{D})$ ratios and conditioning temperatures on starch gelatinization. As conditioning temperature increased, starch gelatinization increased. Due to Enogen Feed corn having increased starch gelatinization when pelleted, we hypothesize that feeding Enogen Feed corn will improve growth performance when fed in a pellet form more than in a meal form when compared to diets with conventional yellow dent corn. Therefore, the objective of this study was to determine the effects of feeding Enogen Feed corn in meal or pellet form on finishing pig growth performance and carcass characteristics.

\section{MATERIALS AND METHODS}

The Kansas State University and Institutional Animal Care and Use committee approved the protocol used in these experiments.

\section{Ingredients and Chemical Analysis}

Conventional U.S. No. 2 dent corn and Enogen Feed corn (Syngenta Seeds; Downers Grove, IL) from a single source was used in this study. Both corn sources were ground to approximately 600 microns using a roller mill (Model DP 900-36, Roskamp, Waterloo, IA) equipped with three roll pairs. Roller mill settings were kept the same throughout the study for conventional yellow dent corn and Enogen Feed corn. Samples of ground corn were taken directly from the roller mill during each feed manufacturing event for each experiment and analyzed (Table 1, Ward Laboratories, Inc., Kearney, NE) for dry matter (method 935.29; AOAC Inc., 2019), starch (Application \#322. 2000), crude protein (method 990.03; AOAC Inc., 2019), ether extract (ANKOM Technology, 2004), acid detergent fiber and neutral detergent fiber (ANKOM Technology, 2005), calcium (method 6.3; Kovar, 2003), and phosphorus (method 6.3; Kovar, 2003).

Particle size analysis was conducted on ground corn samples $(100 \mathrm{~g})$ in duplicate according to the ASADE S319.2 (1995) standard method. Samples were analyzed with $(0.5 \mathrm{~g})$ a dispersing agent (Gilson Company, Inc., Lewis Center, OH). Sieve stacks contained agitators and were placed in the Ro-Tap (Model RX-29, W. S. Tyler Industrial Group, Mentor, $\mathrm{OH}$ ) machine for $15 \mathrm{~min}$.

Representative diet samples from each manufacturing event were obtained from each treatment within experiment and stored at $-20{ }^{\circ} \mathrm{C}$ until analysis. All manufacturing events occurred on the same days to use the same lots of corn for both the meal and pelleted diets. Samples were analyzed (Table 2, Ward Laboratories, Inc., Kearney, NE) for dry matter, crude protein, acid detergent fiber, neutral detergent fiber, $\mathrm{Ca}$, and $\mathrm{P}$ using the same procedures as used for ground grain samples.

All experimental diets were manufactured at Hubbard Feeds (Columbus, NE) from January until March. The pellet mill production rate was held constant at $6.5 \mathrm{ton} / \mathrm{h}$. Target conditioner temperature was set at $82.2{ }^{\circ} \mathrm{C}$. Truelock et al. (2020) evaluated pelleting Enogen Feed corn compared to conventional yellow dent corn. The authors observed that when pelleting Enogen Feed corn to increased conditioner temperatures, there was increased starch gelatinization compared to

Table 1. Chemical analysis of ground $\operatorname{corn}^{a, b}$

\begin{tabular}{lcc}
\hline \hline Item & Conventional $^{c}$ & Enogen Feed corn $^{d}$ \\
\hline Dry matter & 88.20 & 87.50 \\
Crude protein & 9.00 & 8.50 \\
Ether extract & 4.15 & 4.03 \\
Ash & 1.43 & 1.54 \\
Acid detergent fiber & 2.58 & 3.30 \\
Neutral detergent fiber & 8.25 & 8.38 \\
Starch & 71.85 & 71.93 \\
Ca & 0.05 & 0.05 \\
$\mathrm{P}$ & 0.24 & 0.25 \\
\hline
\end{tabular}

${ }^{a}$ Ground corn samples were taken from the roller mill at time of feed manufacturing. Values represent the mean of two samples.

${ }^{b}$ All samples were sent to Ward Laboratories, (Kearney, NE), for chemical analysis.

'Yellow dent corn.

${ }^{d}$ Enogen ${ }^{\circledR}$ Feed corn, Syngenta Seeds, LLC, Downers Grove, IL. 
Table 2. Chemical analysis of complete $\operatorname{diets}^{a, b}$

\begin{tabular}{lccccc}
\hline \hline & \multicolumn{2}{c}{ Meal diets $^{c}$} & & \multicolumn{2}{c}{ Pelleted diets } \\
\cline { 2 - 3 } \cline { 5 - 6 } Item, \% & $\begin{array}{c}\text { Conven- } \\
\text { tional }^{d}\end{array}$ & $\begin{array}{c}\text { Enogen } \\
\text { Feed corn }^{e}\end{array}$ & $\begin{array}{c}\text { Conven- } \\
\text { tional }\end{array}$ & $\begin{array}{c}\text { Enogen } \\
\text { Feed corn }\end{array}$ \\
\hline Grower $^{f}$ & & & & \\
Dry matter & 88.2 & 90.1 & & 88.1 & 87.9 \\
Crude protein & 14.9 & 14.8 & & 15.0 & 15.2 \\
Ether extract & 4.1 & 4.1 & & 5.9 & 4.8 \\
Ash & 3.8 & 3.4 & & 3.4 & 3.4 \\
Acid detergent & 2.5 & 3.4 & & 3.0 & 3.6 \\
$\quad$ fiber & & & & \\
Neutral deter- & 6.0 & 7.6 & & 6.0 & 7.9 \\
$\quad$ gent fiber & & & & \\
Starch & 51.5 & 50.3 & & 47.1 & 48.1 \\
Finisher & & & & & \\
Dry matter & 88.5 & 90.2 & & 90.2 & 91.3 \\
Crude protein & 14.8 & 15.3 & & 13.7 & 14.5 \\
Ether extract & 4.2 & 4.1 & & 4.3 & 4.5 \\
Ash & 3.3 & 3.3 & & 3.4 & 3.6 \\
Acid detergent & 2.4 & 2.6 & 2.9 & 2.9 \\
$\quad$ fiber & & & & & \\
Neutral deter- & 6.8 & 7.7 & 7.2 & 6.7 \\
$\quad$ gent fiber & & & & 52.6 & 50.4 \\
Starch & 51.5 & 49.7 & & \\
\hline
\end{tabular}

${ }^{a}$ Pellets were collected directly from the die at time of feed manufacturing. Values represent the mean of two samples.

${ }^{b}$ Meal diets were taken directly from the feeder 3 days after each phase began. A composite diet was riffle divided and on sample of each treatment per phase was sent for analysis.

${ }^{c}$ Samples were sent to Ward Laboratories, Kearney, NE.

${ }^{d}$ Yellow dent corn.

${ }^{e}$ Enogen ${ }^{\circledR}$, Syngenta Seeds, LLC, Downers Grove, IL.

${ }^{f}$ Grower diets were fed from $\mathrm{d} 0$ to 28.

${ }^{g}$ Finisher diets were fed from d 28 to 72 .

conventional yellow dent corn. To optimize the feed manufacturing, corn needed to be $13 \%$ to $14 \%$ moisture upon arrival to the feed mill to allow moisture rise required to achieve this temperature. Corn moisture was analyzed upon arrival to the feed mill, conventional yellow dent corn averaged 16\% moisture and Enogen Feed corn averaged $17.5 \%$. Getting the conditioner temperature to $82.2{ }^{\circ} \mathrm{C}$ is ideal to achieve maximum starch gelatinization of Enogen Feed corn. When pelleting the diets, the conditioning temperature averaged $68.4^{\circ} \mathrm{C}$ for conventional yellow dent corn and $67.7^{\circ} \mathrm{C}$ for Enogen Feed corn. The hot pellet temperature averaged $75.1{ }^{\circ} \mathrm{C}$ for conventional yellow dent corn averaged and $75.8^{\circ} \mathrm{C}$ for Enogen feed corn. Conditioned mash corn was taken directly from the conditioner (Model $18 \times 120$, Andritz Sprout Bauer, Muncy, PA) to determine the moisture of the conditioned mash. Conditioned mash moisture for the diet containing conventional yellow dent corn averaged
$19.3 \%$ and conditioned mash for Enogen Feed corn diets averaged $20.1 \%$. The conditioned mash moisture shows the amount of moisture added to the mash when passing through the conditioner. For optimal pelleting, conditioned mash moisture should be between $18 \%$ and $20 \%$ for the pellets to move through die with less friction. A $4.8 \mathrm{~mm}$ $\times 3.2 \mathrm{~cm}$ die was used during pelleting, and pellets were taken directly from the die (Model 26W - 300 HL, Sprout Waldron, Tyler, TX), allowed to cool and analyzed for pellet durability index (PDI) using a NHP100 with a 30 -sec run time and a 100-g sample with a filter. Pellets were sifted before and after analysis for separation of fines and pellets using a U.S. \#6 standard sieve. Air temperature and pressure within the NHP100 were recorded throughout the analysis. During feed manufacturing, completed pellets were taken directly from the die to measure hot pellet temperature and chemical analysis (Table 4). Pellets were taken directly from feeders using a grain probe to measure percentage fines.

\section{Animals and Diets}

Treatments were arranged in a $2 \times 2$ factorial with main effects of corn source (conventional yellow dent corn or Enogen Feed corn) and diet form (pellet or meal). Enogen Feed corn replaced conventional yellow dent corn on an equal weight basis (Table 3).

The experiment was conducted at the Kansas State University Swine Teaching and Research Center (Manhattan, KS). Pens of pigs were allotted to one of four dietary treatments in a randomized complete block design with $\mathrm{BW}$ as the blocking factor with eight pigs per pen, four barrows and four gilts, and nine pens per treatment. Diets were fed in either mash or pellet form for 72 $\mathrm{d}$, split into two separate phases, grower and finisher phase. A total of 288 pigs (line $241 \times 600$; DNA, Columbus, NE; initially $53.43 \pm 0.5 \mathrm{~kg}$ ) were used in a 72-d trial. The facility was totally enclosed and environmentally regulated, containing 36 pens. Each pen $(3.00 \times 2.44 \mathrm{~m})$ was equipped with a dry, single-sided feeder (Farmweld, Teutopolis, IL) with two feeder spaces and a 1-cup waterer. Pens were located over a completely slatted concrete floor with a 1.22-m deep pit underneath for manure storage. A robotic feeding system (FeedPro; Feedlogic Corp., Wilmar, MN) was used to deliver and record daily feed additions to each individual pen. Pens were equipped with adjustable gates to allow space allowance per pig to be maintained if a 
Table 3. Diet composition, (as-fed basis)

\begin{tabular}{|c|c|c|}
\hline Ingredient, $\%$ & Grower $^{a}$ & Finisher $^{b}$ \\
\hline$\overline{\text { Corn }^{c}}$ & 79.60 & 83.05 \\
\hline Soybean meal, $46.5 \% \mathrm{CP}$ & 16.50 & 13.10 \\
\hline Corn oil & 1.50 & 1.50 \\
\hline Salt & 0.50 & 0.50 \\
\hline $\begin{array}{l}\text { Monocalcium phosphate, } \\
21 \% \mathrm{P}\end{array}$ & 0.40 & 0.35 \\
\hline Calcium carbonate & 0.85 & 0.85 \\
\hline L-Lysine $\mathrm{HCl}$ & 0.30 & 0.30 \\
\hline L-Threonine & 0.10 & 0.11 \\
\hline L-Tryptophan & 0.015 & 0.02 \\
\hline DL-Methionine & 0.03 & 0.015 \\
\hline Phytase $^{d}$ & 0.02 & 0.02 \\
\hline Selenium premix & 0.05 & 0.05 \\
\hline Trace mineral premix ${ }^{e}$ & 0.08 & 0.08 \\
\hline Vitamin $_{\text {premix }}{ }^{f}$ & 0.05 & 0.05 \\
\hline Total & 100 & 100 \\
\hline \multicolumn{3}{|l|}{ Calculated analysis } \\
\hline \multicolumn{3}{|l|}{$\begin{array}{l}\text { Standardized ileal digest- } \\
\text { ible (SID) amino acids } \%\end{array}$} \\
\hline Lysine & 0.84 & 0.76 \\
\hline Isoleucine:lysine & 59 & 58 \\
\hline Leucine:lysine & 142 & 148 \\
\hline Methionine:lysine & 30 & 30 \\
\hline Threonine:lysine & 64 & 67 \\
\hline Tryptophan:lysine & 19 & 19 \\
\hline Valine:lysine & 70 & 71 \\
\hline Total lysine, $\%$ & 0.93 & 0.84 \\
\hline Net energy, kcal/kg & 2,548 & 2,588 \\
\hline SID lysine:NE, g/Mcal & 3.31 & 2.94 \\
\hline Crude protein, $\%$ & 14.09 & 12.74 \\
\hline $\mathrm{Ca}, \%$ & 0.49 & 0.47 \\
\hline $\mathrm{P}, \%$ & 0.40 & 0.38 \\
\hline Analyzed Ca:analyzed P & 1.21 & 1.25 \\
\hline
\end{tabular}

${ }^{a}$ Grower diets were fed from d 0 to 28 .

${ }^{b}$ Finisher diets were fed from d 28 to 72 .

${ }^{c}$ Enogen Feed corn replaced conventional corn on an equal weight basis

${ }^{d}$ Axtra PHY 2500 TPT (DuPont, Wilmington, DE) provided an estimated release of $0.15 \%$ available $P$.

${ }^{e}$ Provided per $\mathrm{kg}$ of premix: $160,090 \mathrm{mg} \mathrm{Zn}$ from zinc oxide, 134,000 mg Fe of FeS Monohydrate, 40,000 mg Mn from Manganese sulfate, 13,340 mg Cu from copper sulfate, $666 \mathrm{mg}$ I from EDDI 80\% iodine.

${ }^{f}$ Provided per kg of premix: 24,255 IU vitamin A, 4,410 IU vitamin $\mathrm{D}, 132,268 \mathrm{IU}$ vitamin $\mathrm{E}, 13,228$ vitamin $\mathrm{K}, 110.2 \mathrm{mg}$ vitamin $\mathrm{B}_{12}$, 99,212 $\mathrm{mg}$ niacin, 90,390 $\mathrm{mg}$ pantothenic acid, 17,640 $\mathrm{mg}$ riboflavin.

pig died or was removed during the experiment. All experimental pens of pigs were weighed, and feed disappearance was measured every two weeks to calculate average daily gain (ADG), average daily feed intake (ADFI), and gain to feed ratio $(\mathrm{G}: \mathrm{F})$.

On d 72, pigs were individually tattooed with a unique ID number, and a radio frequency identification transponder was inserted into the right ear to allow carcass measurements to be recorded on a pig basis. Final pen weights and individual pig weights were taken, and pigs were transported approximately $2.5 \mathrm{~h}$ to a commercial packing plant (Triumph Foods, St. Joseph, MO) and held in lairage for approximately $7 \mathrm{~h}$ before slaughter. At the plant, hot carcass weight $(\mathrm{HCW})$ was determined immediately after evisceration. Backfat and loin depth were measured with an optical probe (Fat-O-Meter, SFK, Herley, Denmark) inserted between the third and fourth rib (counting from the ham end of the carcass) at a distance approximately $7 \mathrm{~cm}$ from the dorsal midline. Percentage lean was calculated using proprietary equations from the packing plant. Carcass yield was calculated by dividing the individual $\mathrm{HCW}$ obtained from the packing plant by the individual final live weight measured at the farm.

\section{Statistical Analysis}

Treatments were analyzed as randomized complete block design for two-way ANOVA using the lmer function from the lme4 package in $\mathrm{R}$ version 3.5.1 (2018-07-2) with pen considered the experimental unit, body weight as the blocking factor, and treatment as fixed effect. The main effects of corn source and diet form, as well as their interactions, were tested. Differences between treatments were considered significant at $P \leq 0.05$ and marginally significant at $0.05<P \leq 0.10$.

\section{RESULTS}

\section{Chemical Analysis}

This experiment was conducted in January through March, with relatively new crop corn. Whole corn at the mill averaged 17\% moisture. Samples were collected throughout the study and stored before sending for proximate analysis. The chemical analysis for ground corn was similar for both corn sources (Table 1). Ground corn was collected at each manufacturing event, approximately five events, and particle size was analyzed. Corn particle size was analyzed with the inclusion of dispersing agent. In both the grower and finisher phases, Enogen Feed corn tended to have slightly greater ground corn particle size compared to the conventional yellow dent (Table 4).

Conditioning temperature for both corn sources was lower than targeted during the grower and finisher feed manufacturing process. This result could be because the moisture of the corn was higher than expected upon arrival to the feed mill as previously 
Table 4. Feed manufacturing parameters for conventional and Enogen Feed corn ${ }^{a}$

\begin{tabular}{|c|c|c|c|c|}
\hline \multirow[b]{2}{*}{ Item } & \multicolumn{2}{|c|}{ Grower } & \multicolumn{2}{|c|}{ Finisher } \\
\hline & Conventional $^{b}$ & Enogen Feed corn ${ }^{c}$ & Conventional & Enogen Feed corn \\
\hline$\overline{\text { Particle size, } \mu \mathrm{m}^{d}}$ & 690 & 771 & 605 & 632 \\
\hline Sgw & 2.85 & 2.75 & 3.21 & 3.23 \\
\hline Conditioner mash moisture, $\%$ & 19.82 & 20.16 & 18.89 & 20.03 \\
\hline Conditioning temperature, ${ }^{\circ} \mathrm{C}$ & 68.6 & 66.4 & 68.2 & 68.9 \\
\hline Hot pellet temperature, ${ }^{\circ} \mathrm{C}$ & 75.4 & 76.7 & 74.8 & 74.8 \\
\hline Pellet durability index ${ }^{e}, \%$ & 53.1 & 63.5 & 56.2 & 53.1 \\
\hline Finesf,$\%$ & 46.55 & 54.42 & 36.03 & 22.04 \\
\hline
\end{tabular}

${ }^{a}$ A double pass conditioner (Model $18 \times 120$, Andritz Sprout Bauer, Muncy, PA) was used, with a 4.8 mm die on the pellet mill (Model 26W $300 \mathrm{HL}$, Sprout Waldron, Tyler, TX). Production rates were held constant for all three dietary phases at 6.5 ton/h. Values represent the mean of two samples per phase.

${ }^{b}$ Yellow dent corn.

${ }^{c}$ Enogen $^{\circledR}$, Syngenta Seeds, LLC, Downers Grove, IL.

${ }^{d}$ Particle size analysis was measured on ground corn samples taken directly from the roller mill at each manufacturing event.

${ }^{e}$ All pellets were cooled then analyzed for PDI using the NHP100 with a 30 -sec run time and a 100-g sample with a filter. Pellets were sifted before and after analysis for separation of fines and pellets using a U.S. \#6 standard sieve. Air temperature and pressure within the NHP100 were recorded throughout the experiment.

${ }^{f}$ Pellets were taken directly from the feeder using a grain probe for analysis of percent fines.

stated. The higher corn moisture content resulted in a conditioning temperature of $66-68{ }^{\circ} \mathrm{C}$ and a hot pellet temperature of $74-76^{\circ} \mathrm{C}$. For PDI samples collected at the mill, Enogen Feed corn has a 10-percentage unit greater PDI than conventional yellow dent corn in the grower phase, with no major differences between the corn sources in the finisher phase. During the grower phase, there was no difference in percent fines in the pelleted feed, but during the finisher phase, pellets with Enogen Feed corn had increased percent fines compared to conventional yellow dent corn. Grower diets had increased percent fines compared to pellets in the finisher phase. Also, complete pelleted diets were generally similar in chemical analysis within the grower and finisher phases; however, diets for the grower and finisher phases containing the Enogen Feed corn tended to have increased neutral detergent fiber and slightly higher crude fiber compared to the diets containing the conventional yellow dent corn (Table 4).

\section{Growth Performance}

There was no evidence for interactions other than during the finisher phase, where there was a tendency for a corn source $\times$ diet form interaction $(P=0.091$; Tables 5 and 6$)$ for G:F. Pelleting did not improve $\mathrm{G}: \mathrm{F}$ in pigs fed conventional corn but did in pigs fed Enogen Feed corn. Pigs fed conventional yellow dent meal diets had similar G:F to pigs fed conventional yellow dent corn that was pelleted. For carcass characteristics interactions, there was a tendency for a corn source $\times$ diet form interaction $(P<0.10)$ for backfat depth and percentage lean with pigs fed Enogen Feed corn in meal diets having decreased backfat depth compared with pigs fed the other three diets and pelleting increasing percentage lean in pigs fed conventional corn diets, with pigs fed Enogen Feed corn diets having reduced percentage lean when pelleted.

For the overall experimental period, pigs fed the conventional yellow dent corn tended to have increased $(P=0.077)$ ADG compared to pigs fed Enogen Feed corn, which resulted in a tendency $(P=0.100)$ for an improvement in $\mathrm{G}: \mathrm{F}$. There was no other evidence for difference in performance or carcass characteristics detected between corn sources.

For overall feed form effects, during the grower phase, pigs fed pelleted diets had increased $(P<0.003)$ ADG and G:F compared to those fed meal diets. During the finisher phase, pigs fed pelleted diets had increased ADG $(P=0.049)$ compared to pigs fed meal diets. Overall, pigs fed pelleted diets had improved $(P<0.001)$ ADG and $\mathrm{G}: F$ compared with pigs fed meal diets. For carcass characteristics, pigs fed pelleted diets had increased HCW $(P<0.001)$ compared to pigs fed meal diets with no differences found for other carcass parameters.

\section{DISCUSSION}

Starch is the major storage carbohydrate of cereal grains with corn having a starch content of 
Williams et al.

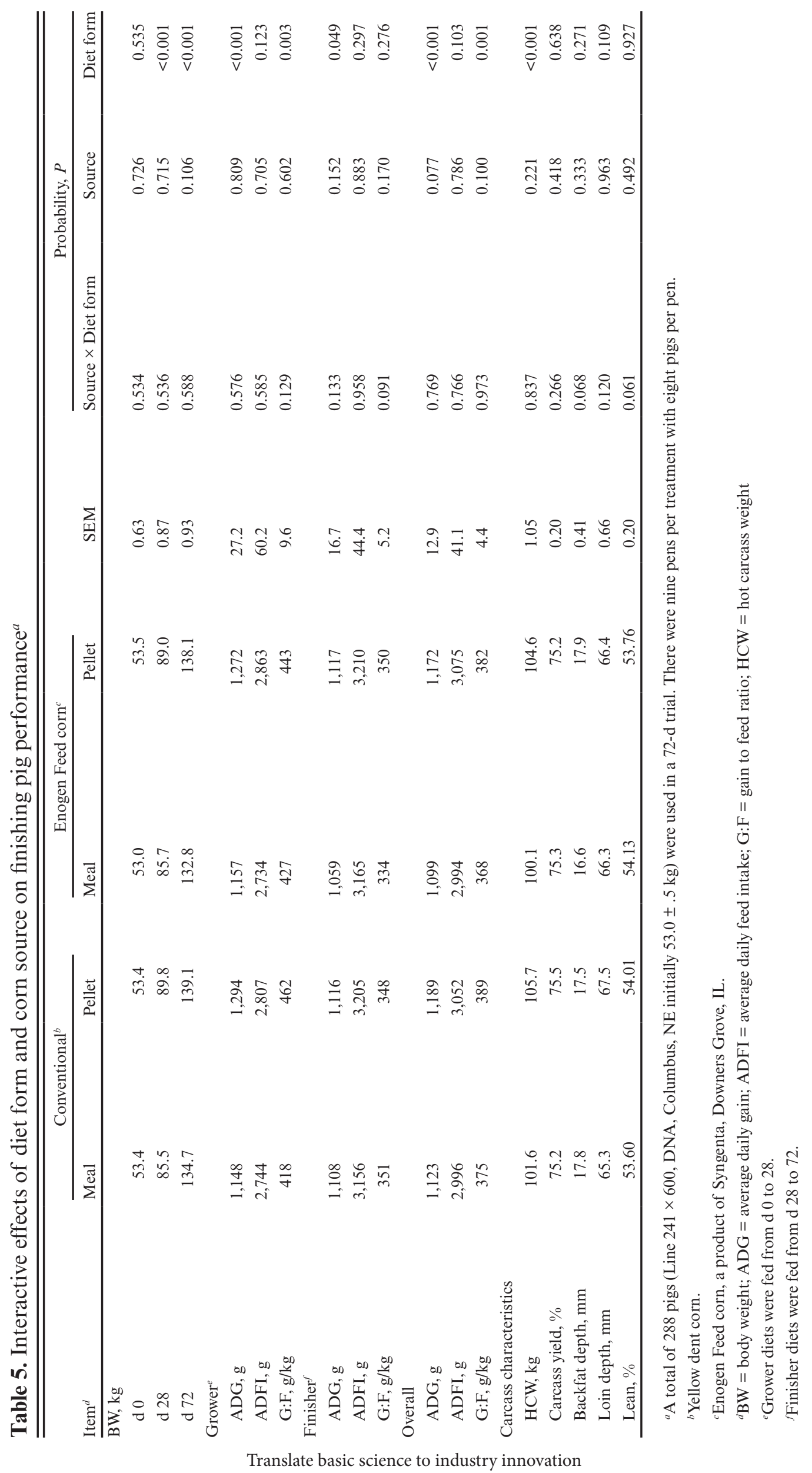




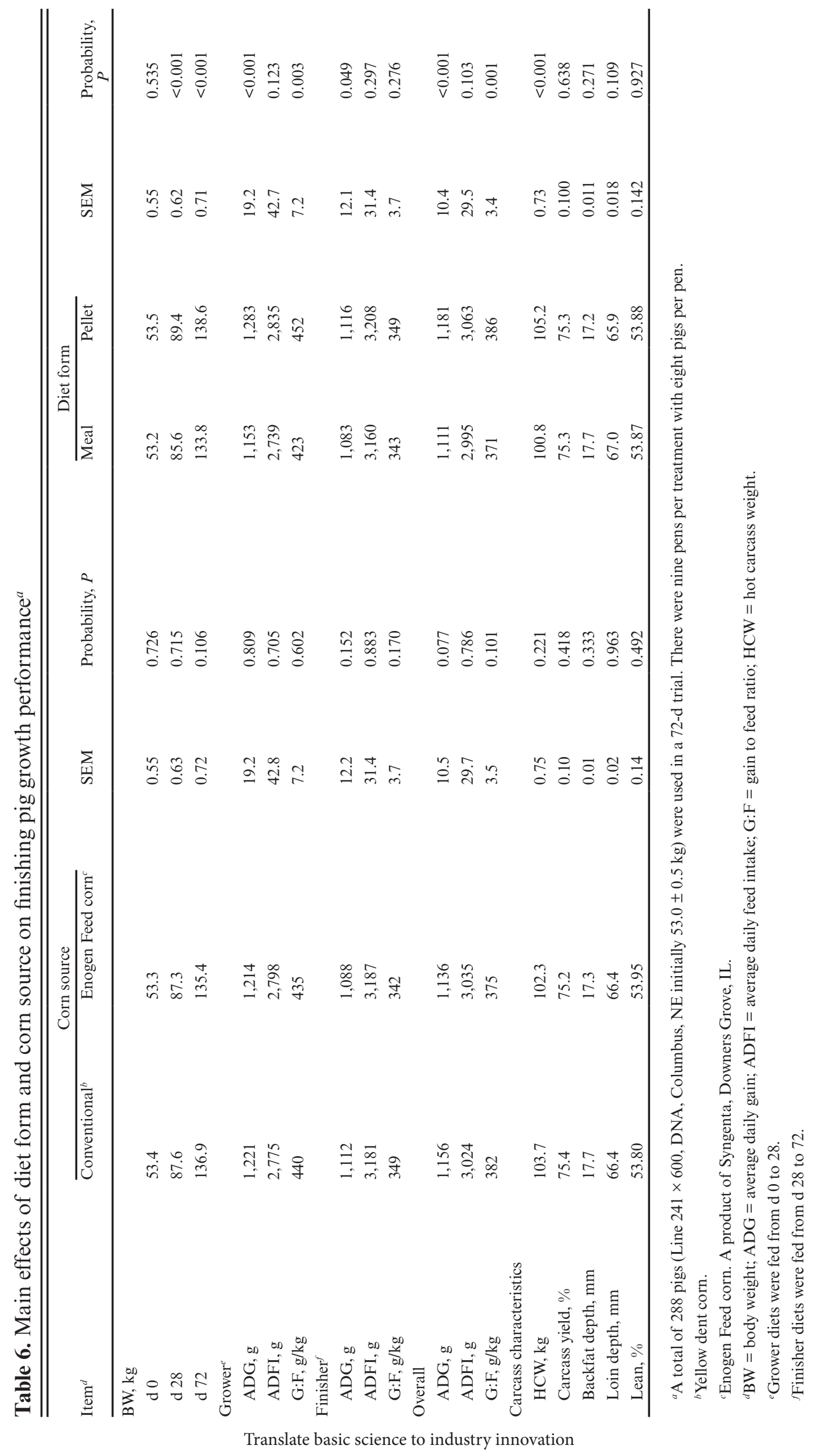


65\% (NRC, 2012). Enogen Feed corn contains an $\alpha$-amylase enzyme trait (SYT-EFC). The SYT-EFC $\alpha$-amylase enzyme is thought to improve starch digestibility by improving conversion of starch into fermentable sugars. Although research on starch digestion of Enogen Feed corn is limited in pigs, a recent study by Jolly-Breithaupt et al. (2016) observed when finishing cattle were fed corn with SYT-EFC $\alpha$-amylase enzyme, there was numerically increased post ruminal starch digestibility compared to cattle fed conventional yellow dent corn. From a different point of view, this increase in sugars could potentially lead to an increased potential for occurrence of the Maillard reaction during the pelleting process. However, a recent study conducted by Dunmire et al. (2020) evaluated pelleting diets with high concentrations of free amino acids and reducing sugars educing sugars. When the diets were pelleted at $85^{\circ} \mathrm{C}$, the authors observed no evidence reduction in amino acid digestibility that would have resulted from Millard reaction. Therefore, it is hypothesized that pelleting conditions and diets used in the experiment conducted herein should not have reduced amino acid digestibility due to the pelleting process.

Research dedicated to evaluating grain processing methods that increase starch digestibility, includes grinding and thermal processing. Starch availability during pelleting is increased through a process known as starch gelatinization. Gelatinization occurs during a four-step process that irreversibly solubilizes raw starch granules through the application of heat and moisture. As mash feed passes through the conditioner, the feed is mixed with heat and moisture in the form of steam, allowing starch granules to swell. As the mash feed exits the conditioner, it passes through the pellet mill die, which generates frictional heat and drives starch gelatinization. Gelatinization of starch during the pelleting process increases the starch availability in the pig as shown by Rojas et al. (2016) which observed an increase in apparent ileal digestibility (AID) of starch from 93.4 in mash diets to $97.7 \%$ in pelleted diets. Lundblad et al. (2011) increased the steam temperature in the conditioner to $90{ }^{\circ} \mathrm{C}$ which resulted in increased starch gelatinization and nursery pig G:F compared with mash diets or steam conditioning at $47{ }^{\circ} \mathrm{C}$ (Lundblad et al., 2011). Truelock et al. (2020) observed that increasing the conditioner temperature from $74{ }^{\circ} \mathrm{C}$ to $85^{\circ} \mathrm{C}$, when pelleting Enogen Feed corn, increases starch gelatinization in the pellet compared to conventional yellow dent corn. In our study, we originally planned to pellet the diets for both conventional yellow dent corn and Enogen feed corn with a conditioner temperature of $85^{\circ} \mathrm{C}$ but were unable to reach the temperature because of the moisture content of both Enogen Feed corn and conventional yellow dent corn. Increased corn moisture content decreases steam uptake and consequently the conditioner cannot reach the desired temperatures.

In this study, pelleting diets resulted in increased ADG and G:F. This agrees with Wondra et al. (1995) who observed a 7\% improvement in G:F when feeding pelleted diets compared with meal. De Jong et al. (2013a, 2013b) and Nemechek et al. (2015) observed a 6\% improvement in G:F when pelleted diets were fed during the finishing period. However, the benefits in G:F when feeding pellets are not always consistent. Meyers et al. (2013) observed no difference in $\mathrm{G}: \mathrm{F}$ when feeding pelleted diets compared to meal. The authors suggest the PDI of the pellets could be the reason for the lack of differences. In the current study, overall G:F was improved by $3.9 \%$ for pigs fed pellets compared to pigs fed meal diets. During the grower stage, a $6.4 \%$ improvement in G:F was observed when pellets were fed compared to meal diets. During the finisher phase, no difference in G:F was observed when comparing pigs fed pelleted diets or meal diets. Reasons for lack of difference in G:F during the finishing period between pigs fed pelleted and meal diets is not fully understood. There did not appear to be any difference in PDI between the grower and finisher phases. Interestingly, the percentage fines for both the conventional yellow dent corn and Enogen Feed corn were higher during the grower phase compared to the finisher phase. The influence of pellet fines on G:F has also been inconsistent in previous research. Langdon (2015) found no impact on $\mathrm{G}: \mathrm{F}$ when pellet fines ranged from 0 to $60 \%$. However, these findings were different from Stark et al. (1993) who reported improved G:F as pellet fines were decreased from $60 \%$ to $0 \%$.

In the current study, we observed a $6 \%$ improvement in ADG when pigs were fed pelleted diets compared to meal diets. These finding are similar to Ball et al. (2015) and Wondra et al. (1995) who observed a 5\% improvement in daily gain when feeding pelleted diets compared to meal diets. Research has shown feeding pelleted swine diets compared to meal diets improves nutrient utilization with higher energy digestibility (Wondra et al., 1995; Lundblad et al., 2011; Ball et al., 2015).

Pigs fed pelleted diets had a $4.2 \%$ improvement in HCW compared to pigs fed meal diets. The increase in ADG and final body weight by pigs fed 
pelleted diets led to the increase in HCW. These results are consistent with Nemechek et al. (2015) who observed an increase in ADG and a numerical improvement in final $\mathrm{BW}$ and $\mathrm{HCW}$ when pigs were fed pelleted diets compared to meal diets. Similarly, Overholt et al. (2016) observed an increase in final BW and $\mathrm{HCW}$ when pigs were fed pelleted diets compared to meal diets. A study conducted by Potter et al. (2010) observed pigs fed pelleted diets had improved carcass yield and a tendency for decreased percentage lean and loin depth. The authors suggested the increase in carcass yield could be attributed to the increased weight gain of pigs fed the pelleted diets. However, in our study, we did not observe any difference on carcass yield, loin depth or lean percentage between pigs fed pelleted or meal diets.

In summary, this study did not find any advantages in finishing pig growth performance when feeding Enogen Feed corn compared to conventional yellow dent corn. The study confirmed previous research that observed feeding pelleted diets to finishing pigs improved ADG and G:F compared to feeding meal diets. However, feeding Enogen Feed corn did not improve growth performance when compared to conventional yellow dent corn whether fed in meal or pelleted diets.

\section{ACKNOWLEDGMENT}

Contribution no. 21-187-J of Kansas Agricultural Experiment Station, Manhattan KS, USA, 66506-0201. The authors wish to thank Syngenta Seeds, LLC, Downers Grove, IL USA for providing the corn and partial financial support.

Conflict of interest statement. The authors declare no conflict of interest.

\section{LITERATURE CITED}

ANKOM Technology. 2004. Rapid determination of oil/fat utilizing high temperature solvent extraction. Fairport, NY: ANKOM Technology.

ANKOM Technology. 2005. Method for determining crude fiber. Fairport, NY: ANKOM Technology.

AOAC Int. 2019. Official methods of analysis AOAC international. 21st ed. Arlington, VA: Association of Official Analytical Chemists.

ASADE Standards. 1995. S319.2: method of determining and expressing fineness of feed materials by sieving. St. Joseph, MI: ASABE.

Ball, M. E. E., E. Magowan, K. J. McCracken, V. E. Beattie, R. Bradford, A. Thompson, and F. J. Gordon. 2015. An investigation into the effect of dietary particle size and pelleting of diets for finishing pigs. Livest. Sci., 173 (2015): 48-54. doi.org/10.1016/j.livsci.2014.11.015
Brinton, M. 2019. Evaluation of alpha amylase containing corn on beef cattle performance and digestibility and double-cropped annual forages following corn harvest. Theses and dissertations in animal science. 189. https:// digitalcommons.unl.edu/animalscidiss/189.

De Jong, J. A., J. M. DeRouchey, M. D. Tokach, R. D. Goodband, S. S. Dritz, and J. L. Nelssen. 2013a. Effects of varying ingredient particle size and diet form on nursery pig growth performance and caloric efficiency. J. Anim. Sci. 91(Suppl. 2):112. (Abstr.).

De Jong, J. A., J. M. DeRouchey, M. D. Tokach, R. D. Goodband, S. S. Dritz, J. L. Nelssen, and C. Hastad. 2013b. Effects of corn particle size, complete diet grinding and diet form on pig performance, caloric efficiency and carcass characteristics. J. Anim. Sci. 91(Suppl.2):216. (Abstr.).

Dunmire, K. M., D. A. Lopez, C. J. Fiehler, C. K. Jones, Y. Li, J. C. Woodworth, M. D. Tokach, C. R. Stark, H. H. Stein, and C. B. Paulk. 2020. Effect of the pelleting process on diet formulations with varying levels of crystalline amino acids and reducing sugars on digestibility in growing pigs. Kansas Agric. Exp. Sta. Res. Rep. 6:10:10-16. https://doi. org/10.4148/2378-5977.8005

Hastad, C. W., M. D. Tokach, R. D. Goodband, J. L. Nelssen, S. S. Dritz, J. M. DeRouchey, and C. L. Jones. 2005. Comparison of yellow dent and NutriDense corn hybrids in swine diets. J. Anim. Sci. 83:2624-2631. doi:10.2527/20 05.83112624x.

Jolly- Breithaupt, M. L., J. L. Harding, J. C. MacDonald, G. E. Erickson, and M. K. Luebbe. 2016. Site and extent of digestion of finishing diets containing syngenta enhanced feed corn. Nebraska Beef Cattle Reports. 886. http://digitalcommons.unl.edu/animalscinbcr/886.

Kovar, J. L. 2003. Method 6.3 inductively coupled plasma spectroscopy. Madison, WI: University of Wisconsin-Extension.

Langdon, J. M. 2015. The genetics of pig feeding behavior. M.S. Thesis, North Carolina State University.

Lundblad, K. K., S. Issa, J. D. Hancock, K. C. Behnke, L. J. McKinney, S. Alavi, E. Prestlokken, J. Fledderus, and M. Sorensen. 2011. Effects of steam conditioning at low and high temperature: expander conditioning and extruder processing prior to pelleting on growth performance and nutrient digestibility in nursery pigs and broiler chickens. Anim. Feed Sci. Technol. 169:208-218. doi:10.1016/j.anifeedsci.2011.06.008

Nemechek, J. E., M. D. Tokach, S. S. Dritz, R. D. Goodband, J. M. DeRouchey, and J. C. Woodworth. 2015. Effects of diet form and type in growth performance, carcass yield, and iodine value of finishing pigs. J. Anim. Sci. 2015.93:4486-4499. doi:10.2527/jas2015-9149

NRC. 2012. Nutrient requirements of swine. 11th ed. Washington, DC: Natl. Acad. Press. doi:10.17226/13298

Ochonski, P., F. Wu, M. D. Tokach, J. M. DeRouchey, S. S. Dritz, R. D. Goodband, J. C. Woodworth, and J. L. Lattimer. 2021. Evaluation of Enogen Feed Corn on growth performance and carcass characteristics of finishing pigs. Transl. Anim. Sci. 5:1-8. doi:10.1093/tas/txab052.

O'Quinn, P. R., J. L. Nelssen, R. D. Goodband, D. A. Knabe, J. C. Woodworth, M. D. Tokach, and T. T. Lohrmann. 2000. Nutritional value of a genetically improved high-lysine, high-oil corn for young pigs. J. Anim. Sci. 78:21442149. doi: $10.2527 / 2000.7882144 x$. 
Overholt, M. F., J. E. Lowell, E. K. Arkfeld, I. M. Grossman, H. H. Stein, A. C. Dilger, and D. D. Boler. 2016. Effects of pelleting diets without or with distillers' dried grains with solubles on growth performance, carcass characteristics, and gastrointestinal weights of growing-finishing barrows and gilts. J. Anim. Sci. 94:2172-2183. doi:10.2527/jas.2015-0202.

Potter, M. L., S. S. Dritz, M. D. Tokach, J. M. DeRouchey, R. D. Goodband, J. L. Nelssen, and J. A. Barnes. 2010. Effects of meal or pellet diet form on finishing pig performance and carcass characteristics. J. Anim. Sci. 88(E-Suppl.3):181. (Abstr.)

Rojas, O. J., E. Vinyeta, and H. H. Stein. 2016. Effects of pelleting, extrusion, or extrusion and pelleting on energy and nutrient digestibility in diets containing different levels of fiber and fed to growing pigs. J. Anim. Sci. 94:1951-1960. doi:10.2527/jas.2015-0137.

Truelock, C. N., M. D. Tokach, C. R. Stark, and C. B. Paulk. 2020. Pelleting and starch characteristics of diets containing different corn varieties. Transl. Anim. Sci. 4:1-7. doi:10.1093/tas/txaa189.

Stark, C. R., R. H. Hines, K. C. Behnke, and J. D. Hancock. 1993. Pellet quality affects growth performance of nursery and finishing pigs. Kansas Agric. Exp. Sta. Res. Rep. 0(10), 71-74). doi:10.4148/2378-5977.6372

Williams, H. R., M. D. Tokach, J. M. DeRouchey, R. D. Goodband, J. C. Woodworth, S. S. Dritz, and J. T. Gebhardt. 2020. The influence of particle size and Enogen ${ }^{\circledR}$ Feed corn and conventional yellow dent corn on nursery and finishing pig performance, carcass characteristics and stomach morphology. In review, Trans. Anim. Sci.

Wondra, K. J., J. D. Hancock, K. C. Behnke, R. H. Hines, and C. R. Stark. 1995. Effects of particle size and pelleting and pelleting on growth performance, nutrient digestibility, and stomach morphology in finishing pigs. J. Anim. Sci. 73, 757-763. doi:10.2527/1995. $733757 x$ 